\title{
Preparation of Organic Zn-Phthalocyanine-Based Semiconducting Materials and Their Optical and Electrochemical Characterization
}

\author{
Amira Hajri, Sarra Touaiti, and Bassem Jamoussi \\ Laboratoire de Chimie Organique et Analytique, Institut Supérieur de l'Education et de la Formation Continue, \\ 43 rue de la Liberté, 2000 Le Bardo, Tunisia \\ Correspondence should be addressed to Amira Hajri; haajriamira@yahoo.fr
}

Received 20 January 2013; Revised 2 April 2013; Accepted 6 April 2013

Academic Editor: Armin Aberle

Copyright (C) 2013 Amira Hajri et al. This is an open access article distributed under the Creative Commons Attribution License, which permits unrestricted use, distribution, and reproduction in any medium, provided the original work is properly cited.

In order to increase the species of organic semiconductors, new Zn-phthalocyanines-based organic materials were synthesized and characterized. The new compounds have been characterized by ${ }^{1} \mathrm{H}$ and ${ }^{13} \mathrm{C}$ using NMR, FTIR, and UV-Vis. The absorption, fluorescence, and electrochemical properties were also studied. Green photoluminescence was observed in dilute solutions. In solid thin films, $\pi-\pi^{*}$ interactions influenced the optical properties, and redshifted photoluminescence spectra were obtained; red emissions for ZnPAL $(647 \mathrm{~nm})$ and $\mathrm{ZnPTr}(655 \mathrm{~nm})$ were found. By cyclic voltammetry, the electrochemical band gap was estimated to be 1.94 and $1.17 \mathrm{eV}$ for $\mathrm{ZnPAl}$ and $\mathrm{ZnPTr}$, respectively. Single-layer diode devices of an indium tin oxide/Znphthalocyanine/aluminum configuration were fabricated and showed relatively low turn-on voltages $(3.3 \mathrm{~V}$ for $\mathrm{ZnPAl}$ and $3 \mathrm{~V}$ for $\mathrm{ZnPTr})$.

\section{Introduction}

Phthalocyanines and related macrocycles have drawn considerable attention as molecular materials that give rise to outstanding electronic and optical properties. These properties arise from their electronic delocalization and make these compounds applicable in different fields of materials science; they are particularly promising as building blocks in nanotechnology. Some of the potential uses for phthalocyanines include nonlinear optical materials [1], liquid crystals [2], Langmuir-Blodgett (LB) films [3], optical data storage (computer recordable DVDs) [4], as electrochromic substances [5], low dimensional metals [6], and gas sensors [7], as photosensitizers [8], in photoelectrochemical cells [9] and electrophotographic applications [10]. Substitution has a strong influence on the $\pi$-electron conjugation of the macromolecule, since it makes salvation easier [11]. In recent years reports predict that a suitable functionalization of the $\mathrm{M}(\mathrm{Pc})$ molecules permits realizing more charge transfer processes decreasing [12], thus, the difference between HOMO and LUMO orbital (gap energy). We described herein, the synthesis and characterization of novel $\mathrm{Zn}$ (II) phthalocyanine derivatives which contain a 1,2,3 triazole unit on each benzo group, and tetra-substituted alkynyl phthalocyanine was synthesis for comparison purpose. ZnPcs structures were characterized by Fourier Transform Infrared Spectrophotometry (FTIR); we studied their electrochemical, optical (by UV-Vis absorption and photoluminescence spectroscopy), and electrical properties.

\section{Experimental}

2.1. Materials and Measurement. $\mathrm{N}, \mathrm{N}^{\prime}$-dimethylformamide (DMF) were freshly used; alcohols and initiator products were purchased from Aldrich. ${ }^{1} \mathrm{H}$-nuclear magnetic resonance (NMR) spectra were obtained using Bruker spectra AC $300 \mathrm{MHz}$. FTIR spectra were acquired on a Mattson 1000 Fourier transform spectrometer as KBr pellets and UVVis spectra on a Unicam UV-Vis spectrometer. Thin layer chromatography (TLC) was performed on precoated silica gel plates $(0.25 \mathrm{~mm}$, Merck). Column chromatography was performed on Merck silica gel having size $0.063-0.200 \mathrm{~mm}$. 


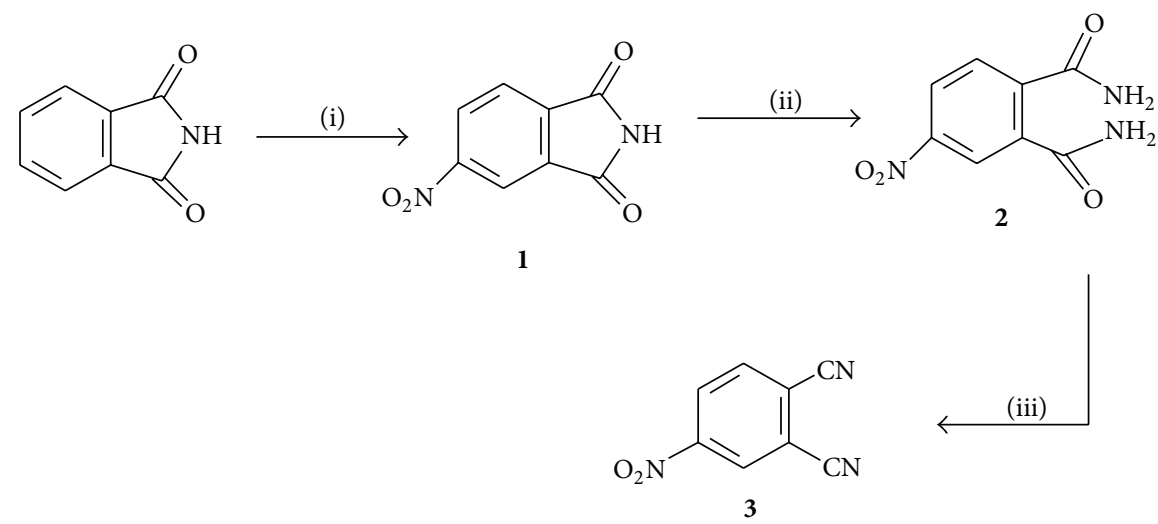

Scheme 1: Reaction conditions: (i) $\mathrm{HNO}_{3}, \mathrm{H}_{2} \mathrm{SO}_{4}, 0^{\circ} \mathrm{C}, 5 \mathrm{~h}$; (ii) $\mathrm{NHOH} 25 \%$; (iii) DMF, $\mathrm{SOCl}_{2}, 0-2^{\circ} \mathrm{C}, 5 \mathrm{~h}$.<smiles>N#Cc1ccc([N+]#N)cc1C#N</smiles><smiles>C#CCc1ccccc1</smiles><smiles>[N]Cc1ccccc1</smiles>

6<smiles>C#CCOc1ccc(C#N)c(C#N)c1</smiles>

5

SCHeme 2: Reaction conditions: (iv) $\mathrm{K}_{2} \mathrm{CO}_{3}$, DMF, $50^{\circ} \mathrm{C}, 72 \mathrm{~h}$; (v) $\mathrm{NaN}_{3}$, DMF, rt, 6 h.

Cyclic voltammetry was recorded using a VoltaLab 10 apparatus from Radiometer driven by the Volta Master software.

Single-layer device elaborated a sandwich structure between an aluminium ( $\mathrm{Al}$ ) cathode and an indium tin oxide (ITO) anode. The solution of phthalocyanine $\left(210^{-6} \mathrm{M}\right.$ in DMF) was deeply coated onto ITO glass to obtain a film about $40 \mathrm{~nm}$ thick after $1 \mathrm{~h}$ of annealing at $100^{\circ} \mathrm{C}$. A thin aluminium layer was deposited by thermal evaporation at $3.10^{-6}$ Torr.

Devices were fabricated and characterized in air at room temperature.

Photoluminescence (PL) spectra were obtained on a spectra physics spectrometer 3900 S with 2017 as stability.

2.2. Synthesis. The synthesis of the macrocycle zinc(II) phthalocyanines $\mathrm{ZnPAl}$ and $\mathrm{ZnPTr}$ begins with the nitration in position $\mathbf{4}$ of phthalimide followed by reaction of the amine hydroxide [13], to form the 4-nitrophthalimide 2; the dehydration by the thionyl chloride in N,N-dimethylformamide [14] leads to 4-nitrophthalonitrile 3 (Scheme 1).

The 4-nitrophthalonitrile 3 reacted with commercial propargyl alcohol $\mathbf{4}$ to obtain compound $\mathbf{5}$ in a reasonable $57 \%$ yield, followed by the amidation reaction to afford benzyl azide 6 (Scheme 1). The 1,3-dipolar cycloaddition of phthalonitrile 5 with compound $\mathbf{6}$ was carried out in DMF at room temperature using $\mathrm{CuBr}$ as a catalyst and triethylamine as a base to prevent the degradation of $\mathrm{Cu}(\mathrm{I})$ (Scheme 2).

Zinc(II) phthalocyanines $\mathbf{8}$ and $\mathbf{9}$ were prepared by cyclotetramerization of phthalonitriles $\mathbf{5}$ and $\mathbf{7}$, respectively, in the presence of anhydrous $\mathrm{Zn}(\mathrm{OAc}) 2$, urea, and nitrobenzene (Scheme 4).

2.2.1. Synthesis of 4-Nitrophthalimide (1). 4-nitrophthalimide 1 was prepared by nitration of phthalimide. Nitric acid $(15.1 \mathrm{~mL}, 0.27 \mathrm{v} / \mathrm{v})$ was slowly added to sulfuric acid $(90.1 \mathrm{~mL})$ $(6: 1)$ in round-bottom flask cooled in an ice bath. The solution was stirred for approximately 30 minutes. Afterward, the ice bath was removed, and the acidic solution was allowed to warm to room temperature. The phthalimide was stirred into the acid solution and heated at $35^{\circ} \mathrm{C}$ until a clear, colorless, and homogenous solution was achieved. As the phthalimide dissolved, the reaction became yellow. The reaction solution was stirred for 4 hours. A powdery white solid was precipitated from ice water, collected via vacuum filtration, and washed with deionized water. The precipitant was stirred under ambient conditions for 12 hours; an $80 \%$ yield was obtained.

RMN ${ }^{1} \mathrm{H}\left(\right.$ DMSO- $\left._{6}\right): \delta: 8.003(\mathrm{~d}, J=5.7 \mathrm{~Hz}, 1 \mathrm{H}) ;$ $8.342(\mathrm{~s}, 1 \mathrm{H}) ; 8.540(\mathrm{~d}, J=6.9 \mathrm{~Hz}, 1 \mathrm{H}) ; 11.761(\mathrm{~s}, 1 \mathrm{H})$. $\mathrm{RMN}^{13} \mathrm{C}\left(\mathrm{DMSO}-\mathrm{d}_{6}\right) \delta$ : 118.16; 124.92; 129.87; 134.42; 137.66; 151.71; 167.61; 167.91. 


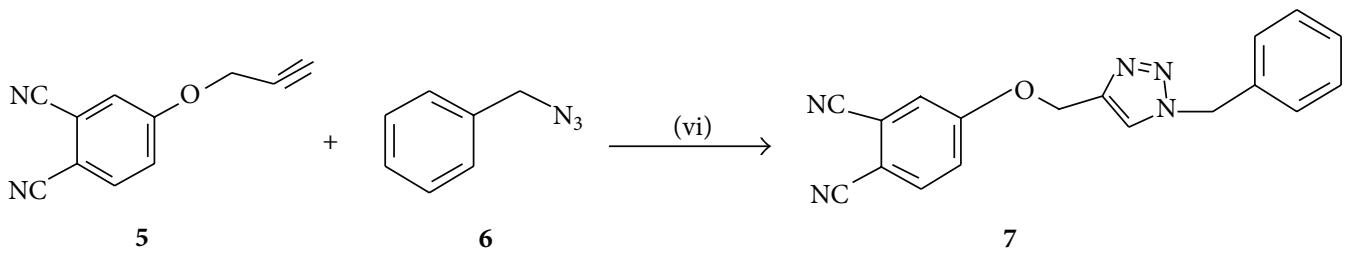

SCHEME 3: Reaction conditions: (vi) $\mathrm{CuBr}_{2} \mathrm{Et}_{3} \mathrm{~N}, \mathrm{rt}, 24 \mathrm{~h}$.

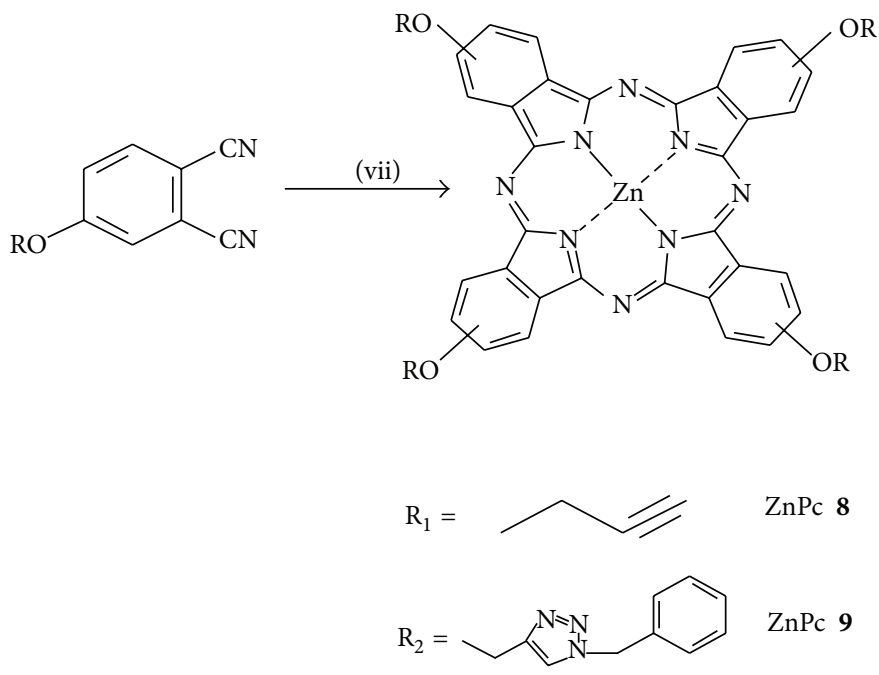

SCHEme 4: Reaction conditions: (viii) $\mathrm{ZnOAc}_{2}$, nitrobenzene, urea, and ammonium molybdate.

2.2.2. Synthesis of 4-Nitrophthalimide (2). 4-Nitrophthalimide was stirred in $32 \%$ ammonia solution $(70 \mathrm{~mL})$ for 24 hours to obtain 4 -nitrophthalimide 2 . The resulting deep yellow product was filtered and washed with cold water until the excess of ammonia could not be detected. The title compound was dried at $110^{\circ} \mathrm{C}$, a $95 \%$ yield.

RMN ${ }^{1} \mathrm{H}(\mathrm{DMSO}-\mathrm{d} 6): \delta: 7.636(\mathrm{~s}, 2 \mathrm{H}) ; 7.704$ (d, $J=$ $8.1,1 \mathrm{H}) ; 8.020(\mathrm{~s}, 1 \mathrm{H}) ; 8.079(\mathrm{~s}, 1 \mathrm{H}) ; 8.297$ (dd, $J=$ $2.4 \mathrm{~Hz}, J=8.7 \mathrm{~Hz}, 1 \mathrm{H}) ; 8.338(\mathrm{~d}, J=2.1,1 \mathrm{H})$. RMN ${ }^{13} \mathrm{C}$ (DMSO-d6) $\delta: 122.35 ; 124.38 ; 129.11 ; 137.19 ; 142 ; 65$; $147.02 ; 167.67 ; 168.67$.

2.2.3. Synthesis of 4-Nitrophthalonitrile (3). The 4-nitrophthalimide 2 was converted to 4 -nitrophthalonitrile via dehydration of the amide by using thionyl chloride and DMF as solvents.

In a two-necked flask of $250 \mathrm{~mL}$ equipped with a mechanical stirrer, under nitrogen atmosphere and at a temperature $0-5^{\circ} \mathrm{C}$, was placed $50 \mathrm{~mL}$ of $\mathrm{N}, \mathrm{N}$-dimethylformamide and was slowly added $20.87 \mathrm{~mL}$ of thionyl chloride $(34 \mathrm{~g}, 0286$ mole). To the reaction mixture $15 \mathrm{~g}$ of 4-nitrophthalimide was added, and the reaction was maintained for 18 hours to complete the dehydration reaction. The 4-nitrophthalonitrile was filtered after precipitation into a mixture of water-ice. the product was dried to yield $86 \%$ of pure product.
$\mathrm{RMN}^{1} \mathrm{H}(\mathrm{DMSO}-\mathrm{d} 6): \delta: 8.439(\mathrm{~d}, J=8.7,1 \mathrm{H}) ; 8.685$ $(\mathrm{dd}, J=2.1 \mathrm{~Hz}, J=8.4 \mathrm{~Hz}, 1 \mathrm{H}) ; 9.033(\mathrm{~d}, J=2.1,1 \mathrm{H})$. $\mathrm{RMN}^{13} \mathrm{C}(\mathrm{DMSO}-\mathrm{d} 6) \delta: 114.55 ; 114.86 ; 116.59 ; 120.22$; $128.52 ; 128.81 ; 135.27 ; 149.69$.

FTIR: 3091 (C-H aromatic), 2242 (CN), 1534 (asymmetric $\mathrm{N}=\mathrm{O}$ band), 1349 (symmetric $\mathrm{N}=\mathrm{O}$ band), 853 $(\mathrm{C}-\mathrm{N})$.

2.2.4. Synthesis of 4-(Propyn-3-yloxy) Phthalonitrile (5). Yield 57\%; 4-nitrophthalonitrile 3 (0.5 g, $2.89 \mathrm{mmol}$ ) was dissolved in anhydrous DMF $(25 \mathrm{~mL})$ under nitrogen, and propargyl alcohol 4 (0.486 g, $8.67 \mathrm{mmol})$ was added. After stirring for $10 \mathrm{~min}$, finely ground anhydrous $\mathrm{K}_{2} \mathrm{CO}_{3}(3.89 \mathrm{~g}, 28.9 \mathrm{mmol})$ was added in portions over $2 \mathrm{~h}$ with stirring. The reaction mixture was stirred at $50^{\circ} \mathrm{C}$ for $72 \mathrm{~h}$ under nitrogen. Then water $(100 \mathrm{~mL})$ was added, and the aqueous phase was extracted with chloroform.

${ }^{1} \mathrm{H}$ nmr (DMSO-d6) $\delta: 3.75$ (s, $\left.1 \mathrm{H}, \mathrm{C} \equiv \mathrm{CH}\right) ; 5.01$ (d, $J=$ $\left.2.4 \mathrm{~Hz}, 2 \mathrm{H}, \mathrm{CH}_{2}-\mathrm{O}-\right) ; 7.51$ (dd, $J=2.4 \mathrm{~Hz}, J=8.7 \mathrm{~Hz}$, $1 \mathrm{H}) ; 7.82(\mathrm{~d}, J=2.7 \mathrm{~Hz}, 1 \mathrm{H}) ; 8.11(\mathrm{~d}, J=8.7 \mathrm{~Hz}, 1 \mathrm{H})$.

${ }^{13} \mathrm{C}$ nmr (DMSO-d6) $\delta$ : 56.6; 79.6; 115.5; 115.6; 116.4; $120.4 ; 120.6 ; 121.4 ; 135.8 ; 159.8$.

2.2.5. Synthesis of Benzyl Azide (6). Yield 70\%; $\mathrm{NaN}_{3}$ (1.54, $23.64 \mathrm{mmol}$ ) was added to a solution of benzyl chloride 4 $(1 \mathrm{~g}, 8 \mathrm{mmol})$ in DMF, and the resulting mixture was stirred 
for $6 \mathrm{~h}$ at room temperature. The product was obtained after purification as a colorless oil.

${ }^{1} \mathrm{H} \mathrm{nmr}\left(\mathrm{CDCl}_{3}\right) \delta: 4.40\left(\mathrm{~s}, 2 \mathrm{H}, \mathrm{CH}_{2} \mathrm{~N}_{3}\right) ; 7.40-7.49(\mathrm{~m}$, $5 \mathrm{H}, \mathrm{Ar}) .{ }^{13} \mathrm{C} \mathrm{nmr}\left(\mathrm{CDCl}_{3}\right) \delta: 54.8,128.5,128.6,128.8$, $128.8,129.4,153.5$.

2.2.6. Synthesis of 1-Benzyl-4-(3,4-dicyanophenoxymethyl)$1 \mathrm{H}-1,2,3$-triazole (7). Yield: $84 \%$; a mixture of 4-(2-propyn1-yn-oxy) phthalonitrile 6 (0.695 g, $0.00374 \mathrm{~mol})$, benzyl azide $5(0.497 \mathrm{~g}, 0.00374 \mathrm{~mol})$, triethylamine $(0.377 \mathrm{~g}$, $0.00374 \mathrm{~mol}$ ), copper bromide (53 $\mathrm{mg}, 0.000374 \mathrm{~mol}$ ), and $15 \mathrm{~mL}$ DMF was taken into round-bottom flask and stirred at room temperature for $24 \mathrm{~h}$ (Scheme 3 ). Progress of the reaction was monitored by TLC. After completion of the reaction, it was diluted with cold water, and the precipitate formed was filtered, washed with water and crystallized from methanol as white powder and recrystallized from methanol as white powder.

\begin{abstract}
${ }^{1} \mathrm{H} \mathrm{nmr}$ (DMSO-d6) $\delta: 5.36$ (s, 2H, $\mathrm{CH}_{2}-\mathrm{O}-$ ), 5.64 (s, $\left.2 \mathrm{H}, \mathrm{CH}_{2}-\mathrm{N}\right), 7.36-7.57(\mathrm{~m}, 6 \mathrm{H}, \mathrm{Ar}), 7.88(\mathrm{~s}, 1 \mathrm{H}, \mathrm{CH}-$ Ar), 8.07 (s, $1 \mathrm{H}, \mathrm{CH}-\mathrm{Ar}), 8.66\left(\mathrm{~s}, 1 \mathrm{H}\right.$, triazole). ${ }^{13} \mathrm{C} \mathrm{nmr}$ (DMSO-d6) $\delta: 52.9,62.1,106.3,115.7$ (2C), 120.5 (2C), 122.1, 128.0, $128.7(4 \mathrm{C}), 135.8\left(2 \mathrm{C}, \mathrm{CH}_{2}-\mathrm{O}\right), 141.6(\mathrm{C}$, $\mathrm{CH}_{2}$-arom), 143.6, 161.3 (C, $\left.\mathrm{O}-\mathrm{CH}_{2}\right)$.
\end{abstract}

2.2.7. Synthesis of Zinc Tetrakis (Propyn-3-yloxy) Phthalocyanine (8). Yield: $20 \% \mathrm{ZnPAl} 8$ was prepared using compound $5(0.179 \mathrm{~g}, 0.984 \mathrm{mmol})$, urea $(0.174 \mathrm{~g}, 2.901 \mathrm{mmol})$, zinc acetate $(0.053 \mathrm{~g}, 0.243 \mathrm{mmol})$, and ammonium molybdate and heated in nitrobenzene at $160^{\circ} \mathrm{C}$ for $8 \mathrm{~h}$. After cooling, the reaction mixture was treated with water. the green dark product that precipitated was filtered off, successively washed with water and hot methanol. UV-Vis $\lambda_{\max }$ in DMF $(680 \mathrm{~nm})$ :

${ }^{1} \mathrm{H}$ nmr (DMSO-d6) $\delta: 2.34$ (s, 4H, C $\equiv \mathrm{CH}$ ); 3.49 (s, $\left.8 \mathrm{H}, \mathrm{CH}_{2}-\mathrm{O}-\right)$; 7.70 (m, 4H, Ar-H); 7.86 (m, 4H, Ar$\mathrm{H}) ; 8.27(\mathrm{~m}, 4 \mathrm{H}, \mathrm{Ar}-\mathrm{H})$. FT-IR $\gamma\left(\mathrm{cm}^{-1}\right): 3280(\mathrm{H}-$ $\mathrm{C} \equiv \mathrm{CH}), 2800$ (CH, aliphatic), $2200(-\mathrm{C} \equiv \mathrm{C}-)$.

2.2.8. Synthesis of Zinc Phthalocyanine (9). Yield: 10\%; Following a similar synthetic procedure, 1-benzyl-4-(3,4dicyanophenoxy)-1H-1,2,3-triazole $7(0.155 \mathrm{~g}, 0.492 \mathrm{mmol})$, urea $(0.087 \mathrm{~g}, 1,450 \mathrm{mmol})$, zinc acetate $(0,026 \mathrm{~g}, 0,121 \mathrm{mmol})$, and ammonium molybdate $(0,012 \mathrm{~g}, 0.01 \mathrm{mmol})$ were suspended in nitrobenzene $(2 \mathrm{~mL})$ and heated at $160^{\circ} \mathrm{C}$ for 8 h. Yield: (10\%) UV-Vis $\lambda$ max in DMF $(700 \mathrm{~nm}) ;{ }^{1} \mathrm{H} \mathrm{nmr}$ (DMSO-d6) $\delta: 5.13$ (s, 8H, $\mathrm{CH}_{2}-\mathrm{O}-$ ), $5.58\left(\mathrm{~s}, 8 \mathrm{H}, \mathrm{CH}_{2}-\mathrm{N}\right)$, 7.67-7.88 (m, 32H, Ar-H/Pc-H), 8.34 (s, 4H, triazole). FT-IR $\gamma$ $\left(\mathrm{cm}^{-1}\right)$ : $3050(\mathrm{CH}$, triazole), $3030(\mathrm{CH}$, aromatic), $2850(\mathrm{CH}$, aliphatic).

\section{Results and Discussion}

\subsection{Optical Properties}

3.1.1. Electronic Absorption Spectra. The ground state electronic spectra are especially useful to identify the structure

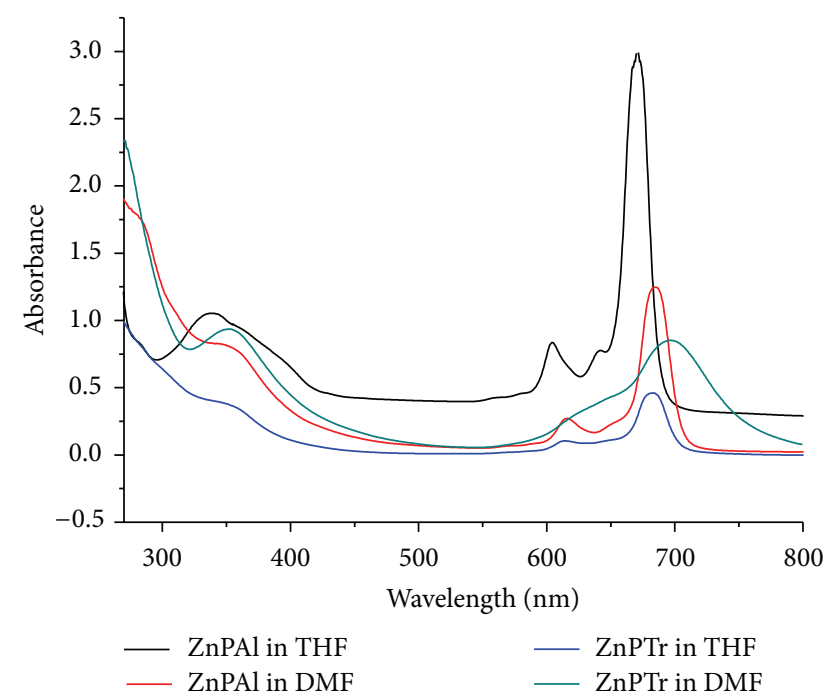

FIgURE 1: UV-Visible absorption spectra of ZnPAl (red line) and $\mathrm{ZnPTr}$ (green line) in DMF solution, $\mathrm{ZnPAl}$ (black line) and $\mathrm{ZnPTr}$ (blue line) in THF solution $\left(410^{-5} \mathrm{M}\right)$.

of the phthalocyanines. Generally, UV-Vis spectra of phthalocyanines show typical electronic spectra with two strong absorption bands known as $\mathrm{Q}$ and $\mathrm{B}$ bands. The $\mathrm{Q}$ band in the visible region at ca. $600-750 \mathrm{~nm}$ is attributed to the $\pi-\pi^{*}$ transition from the highest occupied molecular orbital (HOMO) to the lowest unoccupied molecular orbital (LUMO) of the Pc ring and the B band in the UV region at $300-400 \mathrm{~nm}$ $[15,16]$. The ground state electronic absorption spectra of the peripherally tetra-substituted phthalocyanine complexes showed monomeric behavior evidenced by a single (narrow) Q band, typical of nonaggregated metallophthalocyanine complexes in THF and DMF.

The electronic spectra of Zn-phthalocyanine compounds ( $\mathrm{ZnPAl}, \mathrm{ZnPTr}$ ) in DMF and THF are given in Figure 1.

The UV-Vis absorption spectra of $\mathrm{ZnPAl}$ and $\mathrm{ZnPTr}$ in DMF showed intense Q absorption at 685 and $700 \mathrm{~nm}$, respectively. The $\mathrm{Q}$ band absorptions were also observed at $670 \mathrm{~nm}$ and $683 \mathrm{~nm}$, respectively, for ZnPAL and ZnPTr in THF. In addition, the intense $\mathrm{B}$ band absorptions in DMF were observed at $349 \mathrm{~nm}$ for $\mathrm{ZnPAl}$ and $381 \mathrm{~nm}$ for $\mathrm{ZnPTr}$ but $340 \mathrm{~nm}$ for $\mathrm{ZnPAl}$ and $352 \mathrm{~nm}$ for $\mathrm{ZnPTr}$ in THF (Figure 1).

The electronic absorption transitions of these compounds are strongly dependent on the type of the substituent (withdrawing or donating groups) as well as the type of the metal ion and its position (in the centre or on peripheral position) [17].

Peripheral substitution of phthalocyanine by triazole chains gave bathochromic shifts of the $\mathrm{Q}$ band [18-20] in both studied solvents, which can be explained by the concomitant effect of the presence of triazole ring which possesses three nitrogen atoms and, thus, can serve as a ligand to coordinate metals or as a hydrogen bond acceptor and donor. 
TABLE 1: Optical data for ZnPAl and ZnPTr.

\begin{tabular}{|c|c|c|c|c|}
\hline & \multicolumn{2}{|c|}{$\lambda_{\max }(\mathrm{nm})$} & \multirow{2}{*}{$\lambda_{\text {onset }}(\mathrm{nm})$} & \multirow{2}{*}{ Optical band gap $E_{\text {gap }}(\mathrm{ev})$} \\
\hline & B band & Q band & & \\
\hline \multicolumn{5}{|c|}{ Dilute solution in DMF } \\
\hline $\mathrm{ZnPAl}$ & 349 & 685 & 707 & 1.75 \\
\hline $\mathrm{ZnPTr}$ & 381 & 700 & 760 & 1.63 \\
\hline \multicolumn{5}{|c|}{ Dilute solution in THF } \\
\hline $\mathrm{ZnPAl}$ & 340 & 670 & 693 & 1.79 \\
\hline $\mathrm{ZnPTr}$ & 352 & 683 & 705 & 1.76 \\
\hline
\end{tabular}

$\lambda_{\text {max }}:$ wavelength of maximum absorption; $\lambda_{\text {onset }}:$ wavelength of absorption onset; $E_{\text {gap }}$ : optical energy gap.

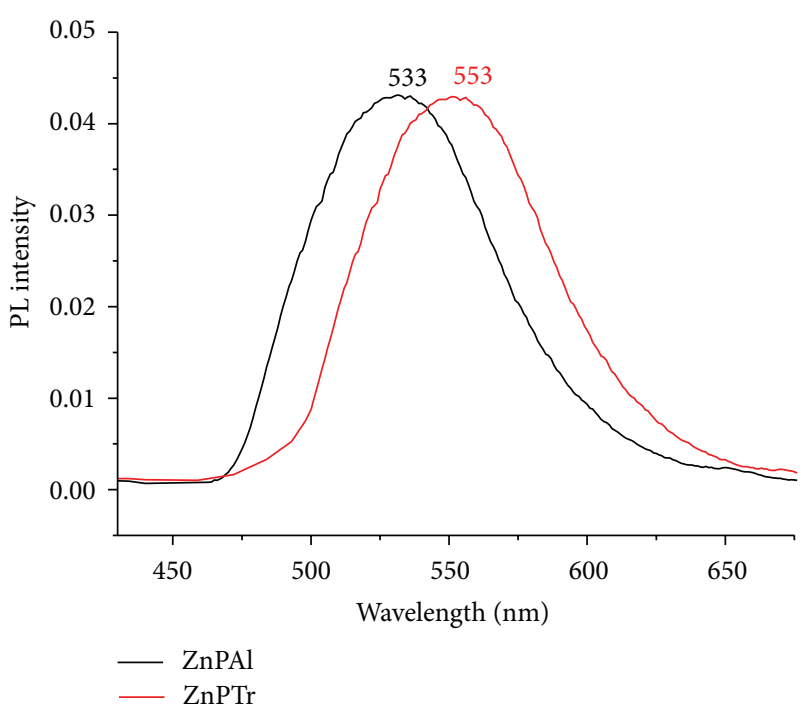

FIGURE 2: PL spectra of $\mathrm{ZnPAl}$ and $\mathrm{ZnPTr}$ (dilute solutions in DMF $210^{-6} \mathrm{M}, \lambda_{\text {exc }}=488 \mathrm{~nm}$ ).

The optical band gaps were estimated from the absorption onset of the phtalocyanines solutions. Table 1 summarizes these spectral data.

3.1.2. Fluorescence Spectra. The fluorescence behavior of zinc phthalocyanine complexes was studied in solution in DMF and in thin solid films, excitation wavelength $\left(\lambda_{\text {exc }}\right)=488 \mathrm{~nm}$. Samples show emission in green region at 533 and $553 \mathrm{~nm}$ for $\mathrm{ZnPAl}$ and $\mathrm{ZnPTr}$, respectively (Figure 2).

The $\pi-\pi^{*}$ stacking of conjugated phthalocyanines also influenced the film emission, and broad, red shifted PL spectra were obtained as a result to excimer formation [21] in comparison with the solution spectra (Figure 2). An important redshift was observed $(647 \mathrm{~nm})$ and $(655 \mathrm{~nm})$, respectively, for $\mathrm{ZnPAl}$ and $\mathrm{ZnPTr}$, and a red emission was obtained (Figure 3).

\subsection{Electrochemistry}

3.2.1. Cyclic Voltammetry. Electrochemistry provides valuable insight into the electronic properties of molecules. This technique provides information on the position of the energy

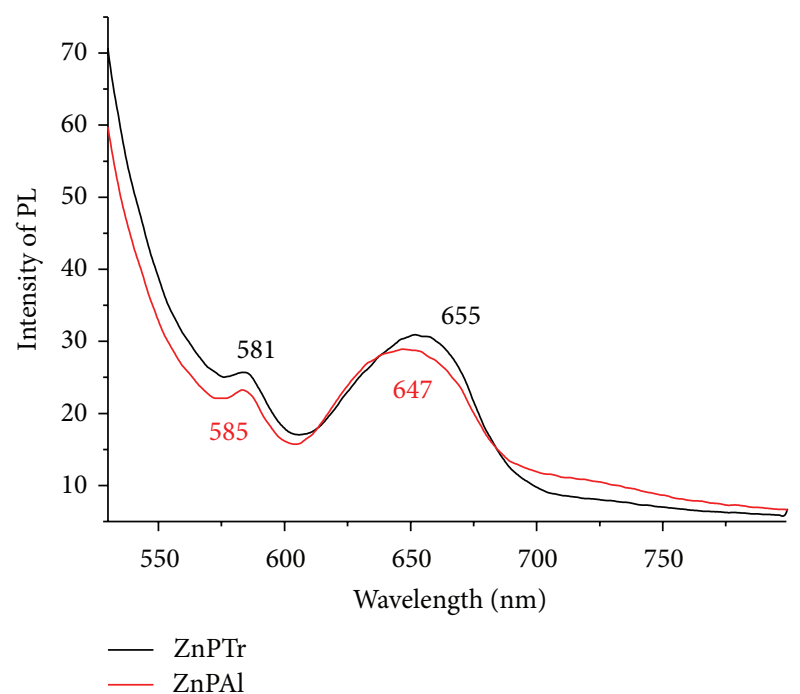

Figure 3: PL spectra of ZnPAl and ZnPTr in thin films $40 \mathrm{~nm}\left(\lambda_{\mathrm{exc}}=\right.$ $488 \mathrm{~nm})$.

levels; in particular the highest occupied molecular orbital (HOMO) and the lowest unoccupied molecular orbital (LUMO) are easily discernible from these measurements.

The glass ITO was used as working electrode and scanned in $\mathrm{LiClO}_{4} /$ dimethylformamide. The voltammograms obtained are shown in Figure 4.

$\mathrm{ZnPAl}$ exhibits two creversible oxidations peaks at 1.05 and $1.32 \mathrm{~V}$. ZnPTr exhibits two quasi-reversible oxidations at 0.9 and $1.35 \mathrm{~V}$ and a reversible reduction peak at $-0.79 \mathrm{~V}$ (Figure 4).

The position of the HOMO of a molecule is probed by determining its anodic potential, while the position of the LUMO is determined by its cathodic potential. These positions can be referenced with respect to the vacuum level by adding $4.8 \mathrm{eV}$ to the onset of the peak (oxidation/reduction) with respect to the ferrocene/ferrocenium $\left(\mathrm{Fc} / \mathrm{Fc}^{+}\right)$redox couple [22]. All processes are ring based since the central $\mathrm{Zn}$ metal is electroinactive $[23,24]$.

The HOMO energy level ( $\left.E_{\text {HOMO }}\right)$, LUMO energy level $\left(E_{\mathrm{LUMO}}\right)$, and the electrochemical gap $\left(E_{\text {gap el }}\right)$ were calculated as follows:

$$
\begin{gathered}
E_{\mathrm{HOMO}}=-\left(V_{\text {onset ox }}-\mathrm{V}_{\mathrm{FOC}}+4.8\right) \mathrm{eV}, \\
E_{\mathrm{LUMO}}=-\left(V_{\text {onset red }}-V_{\mathrm{FOC}}+4.8\right) \mathrm{eV}, \\
E_{\text {gap el }}=\left(E_{\text {LUMO }}-E_{\mathrm{HOMO}}\right) \mathrm{eV},
\end{gathered}
$$

where $V_{\mathrm{FOC}}$ is the ferrocene half-wave potential $(0.9 \mathrm{~V})$, $V_{\text {onset ox }}$ is the material oxidation onset, and $V_{\text {onset red }}$ is the material reduction onset, all measured versus SCE. The calculated $E_{\mathrm{HOMO}}, E_{\mathrm{LUMO}}$, and $E_{\text {gap el }}$ values are summarized in Table 2.

3.3. Current-Voltage Measurements. Two single-layer devices with an ITO/ZnPc/aluminum configuration were fabricated to investigate the current-voltage characteristics of the phtalocyanine-based materials. As shown in Figure 5, 


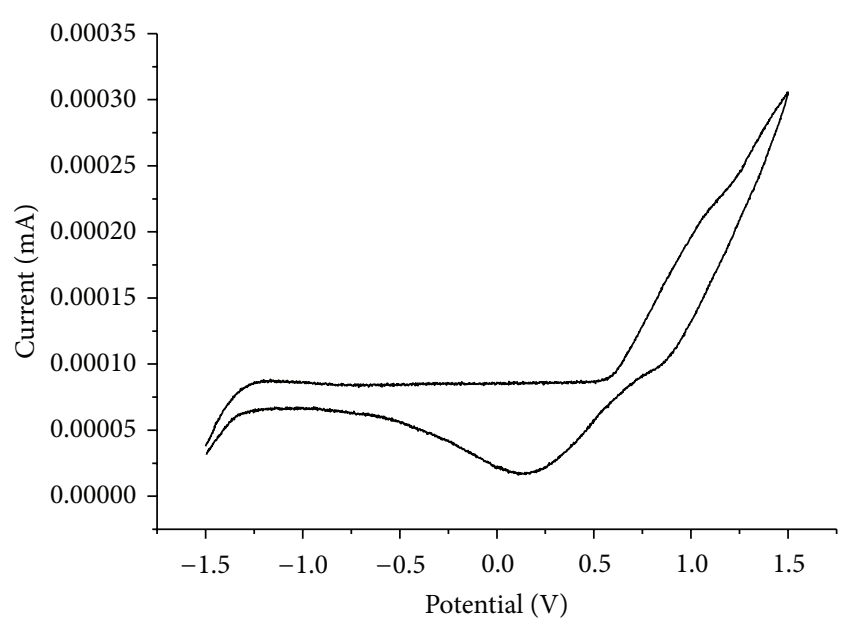

(a)

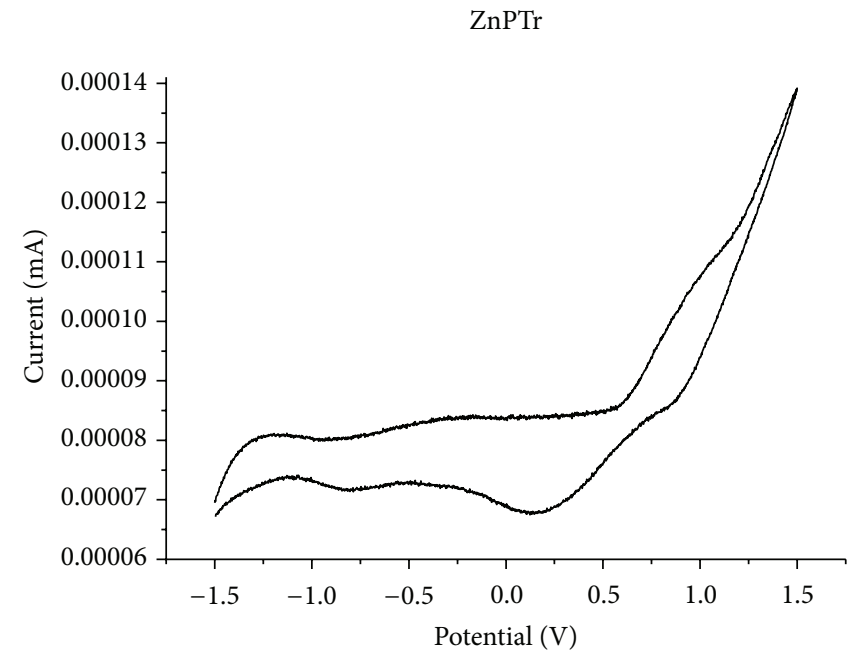

(b)

Figure 4: Cyclic voltammograms of $\mathrm{ZnPAl}$ and $\mathrm{ZnPTr}$ in $0.1 \mathrm{M} \mathrm{LiclO}_{4} / \mathrm{DMF}$ (scan rate: $100 \mathrm{mVs}^{-1}$ working electrode $=\mathrm{ITO}$, auxiliary electrode $=$ platinum wire, and reference electrode $=$ ECS).

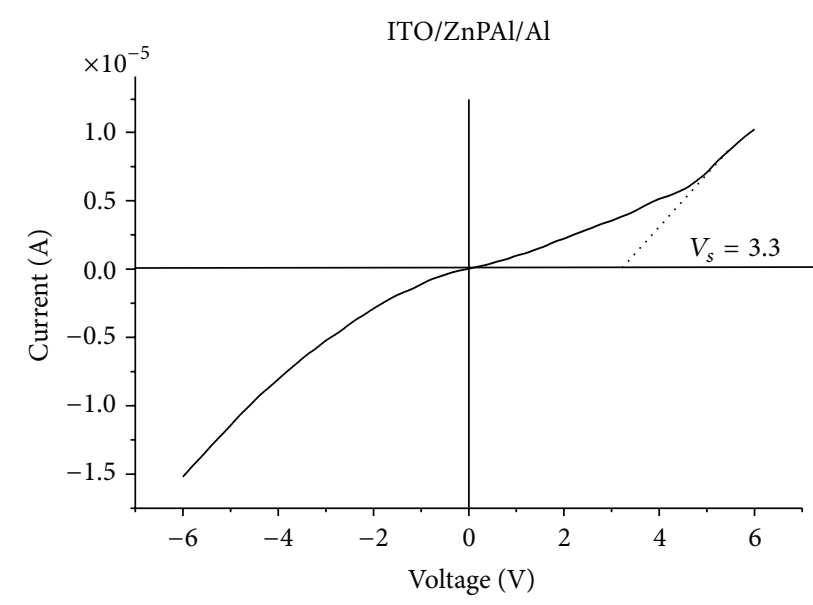

(a)

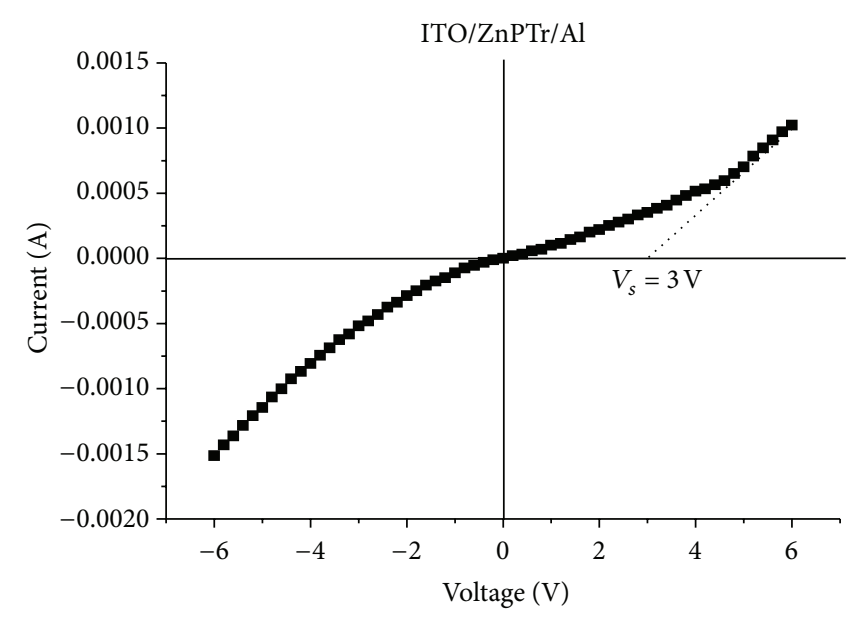

(b)

FIGURE 5: Current-voltage curves for ITO/Zn-phthalocyanine/aluminum diodes.

TABLe 2: Specific $E_{\text {HOMO }}(\mathrm{V}), E_{\mathrm{LUMO}}(\mathrm{V})$, and electrochemical band gap (ev) of $\mathrm{ZnPAl}$ and $\mathrm{ZnPTr}$.

\begin{tabular}{lccc}
\hline Phthalocyanines & $E_{\text {HOMO }}$ & $E_{\text {LUMO }}$ & $E_{\text {gap }}$ \\
\hline ZnPAl & -4.49 & -2.55 & 1.94 \\
ZnPTr & -4.49 & -3.32 & 1.17 \\
\hline
\end{tabular}

the current-voltage curves indicate typical diode behavior with relatively low turn-on voltages of 3 and $3.3 \mathrm{~V}$ for $\mathrm{ZnPTr}$ and $\mathrm{ZnPAl}$, respectively. Nevertheless, no electroluminescence could be recorded for these simple devices. The reason was probably unbalanced charge injection, which increased the probability of radiation less exciton quenching at the electrode phthalocyanine interface $[25,26]$.
Therefore, we believe that the device turn-on voltage indicates the threshold of a hole governed unipolar injection. Work is in progress to build electroluminescent multilayer devices.

\section{Conclusion}

In summary, two semiconductors $\mathrm{Zn}$-phthalocyanines were successfully synthesized and optically and electrochemically characterized. It was shown that the extension of phthalocyanine by triazole ring can increase the absorption bands to $700 \mathrm{~nm}$. In dilute solutions, these complexes presented green emissions. In thin solid films, the interchain $\pi-\pi^{*}$ interactions influenced the optical behavior, and redshifted PL spectra were obtained. The current-voltage characteristics 
of the devices with an ITO/phthalocyanine/aluminum configuration demonstrated typical diode behavior and relatively low turn-on voltages. All these features make these complexes promising active materials for phthalocyanine-based OLEDs.

\section{Conflict of Interests}

The authors confirm that this paper content has no conflict of interests.

\section{Acknowledgment}

This research was supported by the Ministry of Higher Education and Scientific Research, Tunisia.

\section{References}

[1] M. Casstevens, M. Samok, J. Pfleger, and P. N. Prasad, "Dynamics of third-order nonlinear optical processes in LangmuirBlodgett and evaporated films of phthalocyanines," Journal of Chemical Physics, vol. 92, no. 3, article 2019, 6 pages, 1990.

[2] J. F. van der Pol, E. Neeleman, J. W. Zwikker et al., "Homologous series of liquid-crystalline metal free and copper octa- $n$ alkoxyphthalocyanines," Liquid Crystals, vol. 6, no. 5, pp. 577$592,1989$.

[3] H. Schultz, H. Lehmann, M. Rein, and M. Hanack, "Phthalocyaninatometal and related complexes with special electrical and optical properties," Structure and Bonding, vol. 74, pp. 41146, 1991.

[4] J. E. Kuder, "Organic active layer materials for optical recording," Journal of Imaging Science, vol. 32, no. 2, pp. 51-56, 1988.

[5] M. Riou and C. Clarisse, "The rare earth substitution effect on the electrochemistry of diphthalocyanine films in contact with an acidic aqueous medium," Journal of Electroanalytical Chemistry and Interfacial Electrochemistry, vol. 249, no. 1-2, pp. 181-190, 1988.

[6] T. J. Marks, "Electrically conductive metallomacrocyclic assemblies," Science, vol. 227, no. 4689, pp. 881-889, 1985.

[7] R. A. Collins and K. A. Mohammed, "Gas sensitivity of some metal phthalocyanines," Journal of Physics D: Applied Physics, vol. 21, article 154, 1988.

[8] E. Lukyanets, "Phthalocyanines as photosensitizers in the photodynamic therapy of cancer," Journal of Porphyrins and Phthalocyanines, vol. 3, no. 6, article 424, 1999.

[9] T. J. Klofta, J. Danziger, P. Lee, J. Pankow, K. W. Nebesny, and N. R. Armstrong, "Photoelectrochemical and spectroscopic characterization of thin films of titanyl phthalocyanine: comparisons with vanadyl phthalocyanine," Journal of Physical Chemistry, vol. 91, no. 22, pp. 5646-5651, 1987.

[10] S. Takano, T. Enokida, A. Kakuta, and Y. Mori, "A new polymorph of metal-free phthalocyanine," Chemistry Letters, vol. 13, no. 12, pp. 2037-2040, 1984.

[11] T. Ceyhan, M. Y. Yüksek, H. G. Yağlioğlu et al., "Synthesis, characterization and nonlinear absorption of novel octakisPOSS substituted metallophthalocyanines and strong optical limiting property of CuPc," Dalton Transactions, pp. 2407-2413, 2008.

[12] R. S. Iglesias, M. Segala, M. Nicolau, and B. Cabezo, "Computational study of the geometry and electronic structure of triazolephthalocyanines," Journal of Materials Chemistry, vol. 12, pp. 1256-1261, 2002.
[13] R. Valentin, W. Luminipa, R. Alina, A. Petrea, A. Viorica, and A. Ana, "Synthesis and characterization of some phthalic acid derivatives precursors for phthalocyanine chromogens," Revista de Chimie, vol. 9, p. 59, 2008.

[14] J. S. Michael, [thesis of doctorate], Faculty of the Virginia Polytechnic Institute and State, Blacksburg, Va, USA, 2006.

[15] T. F. Baumann, M. S. Nasir, J. W. Sibert et al., "solitaire-Porphyrazines: synthetic, structural, and spectroscopic investigation of complexes of the novel binucleating norphthalocyanine2,3-dithiolato ligand," Journal of the American Chemical Society, vol. 118, no. 43, pp. 10479-10486, 1996.

[16] F. Hacıvelioğlu, M. Durmus, S. Yesilot, A. G. Gürek, A. Kılıç, and V. Ahsen, "Synthesis, electronic absorption and fluorescence spectral properties of phenoxycyclotriphosphazene-substituted phthalocyanines," Dyes and Pigments, vol. 79, pp. 14-23, 2008.

[17] G. K. Karaoglan, G. Gümrükçü, A. Koca, A. Gül, and U. Avcıata, "Synthesis and characterization of novel soluble phthalocyanines with fused conjugated unsaturated groups," Dyes and Pigments, vol. 90, no. 1, pp. 11-20, 2011.

[18] N. B. McKeown, Phthalocyanine Materials: Synthesis, Structure and Function, Cambridge University Press, Cambridge, UK, 1998.

[19] M. J. Cook, A. J. Dunn, S. D. Howe, A. J. Thomson, and K. J. Harrison, "Octa-alkoxy phthalocyanine and naphthalocyanine derivatives: dyes with Q-band absorption in the far red or near infrared," Journal of the Chemical Society, Perkin Transactions, vol. 1, no. 8, pp. 2453-2458, 1988.

[20] K. Hiz, N. Jaballah, and M. Chamli, "Synthesis and characterization of new anthracene-based semi-conducting materials," Journal of Materials Science, vol. 47, no. 23, pp. 8067-8075, 2012.

[21] K. Yoshino, M. Hikida, K. Tatsuno, K. Kaneto, and Y. Inuishi, "Emission spectra of phthalocyanine crystals," Journal of the Physical Society of Japan, vol. 34, no. 2, pp. 441-445, 1973.

[22] Y. Arslanoglua, A. Kocab, and E. Hamuryudan, "Synthesis of novel unsymmetrical phthalocyanines substituted with crown ether and nitro groups," Polyhedron, vol. 26, no. 1, pp. 891-896, 2007.

[23] K. Wang, Q. Fu, J. Ma et al., "Synthesis and electrochemical properties of a series of novel tetra(4-benzoyl)phenoxyphthalocyanine derivatives," Science China Chemistry, vol. 55, no. 9, pp. 1872-1880, 2012.

[24] P. W. M. Blom and M. C. J. M. Vissenberg, "Charge transport in poly(p-phenylene vinylene) light-emitting diodes," Materials Science and Engineering: R: Reports, vol. 27, no. 3-4, pp. 53-94, 2000.

[25] K. Hiz, N. Jaballah, and M. Chamli, "Synthesis and characterization of new anthracene-based semiconducting polyethers," Journal of Applied Polymer Science, vol. 119, no. 3, pp. 1443-1449, 2011.

[26] H. Ndayikengurukiye, S. Jacobs, W. Tachelet et al., "Alkoxylated p-phenylenevinylene oligomers: synthesis and spectroscopic and electrochemical properties," Tetrahedron, vol. 53, no. 40, pp. 13811-13828, 1997. 

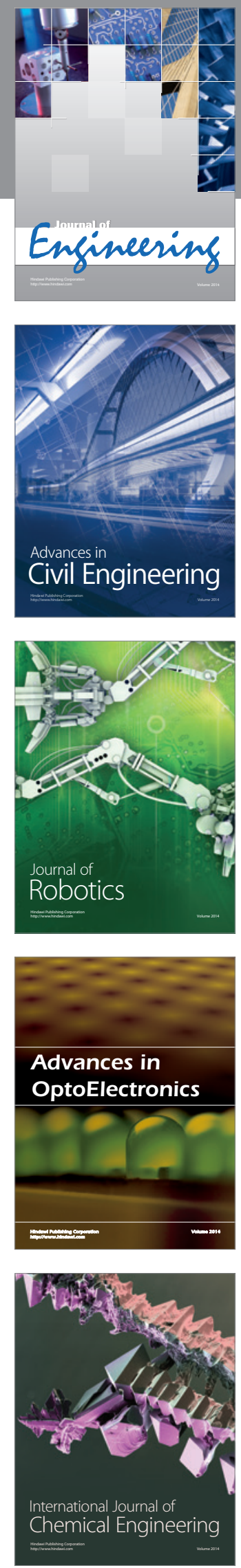

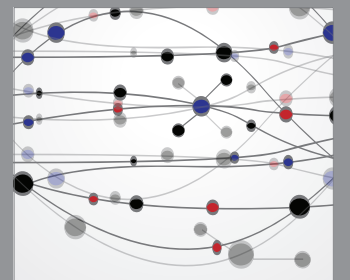

The Scientific World Journal
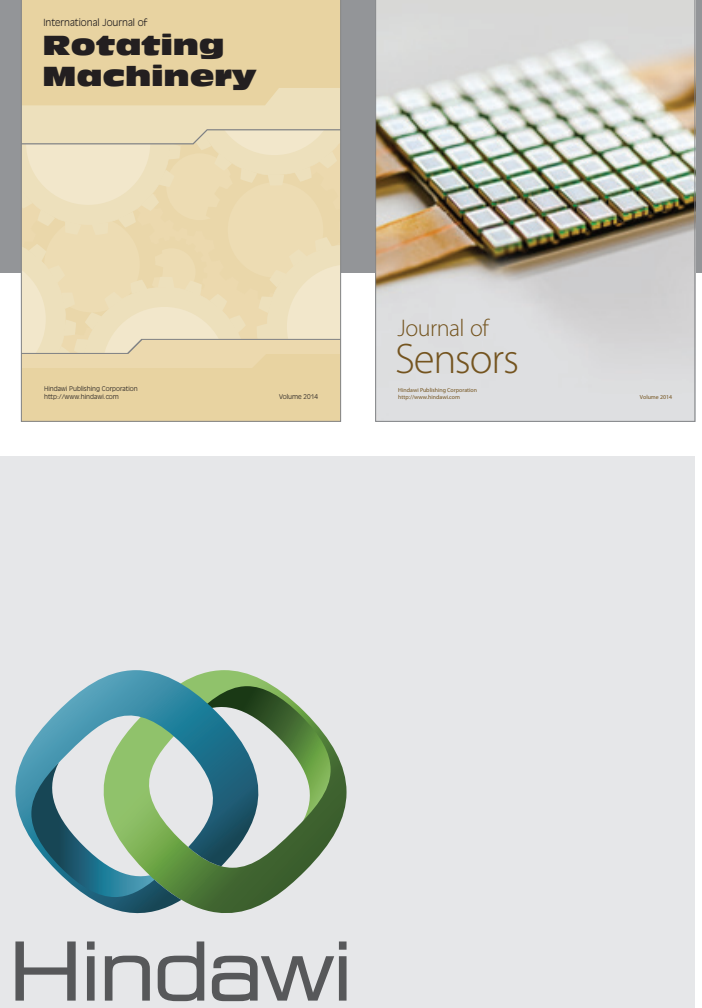

Submit your manuscripts at http://www.hindawi.com
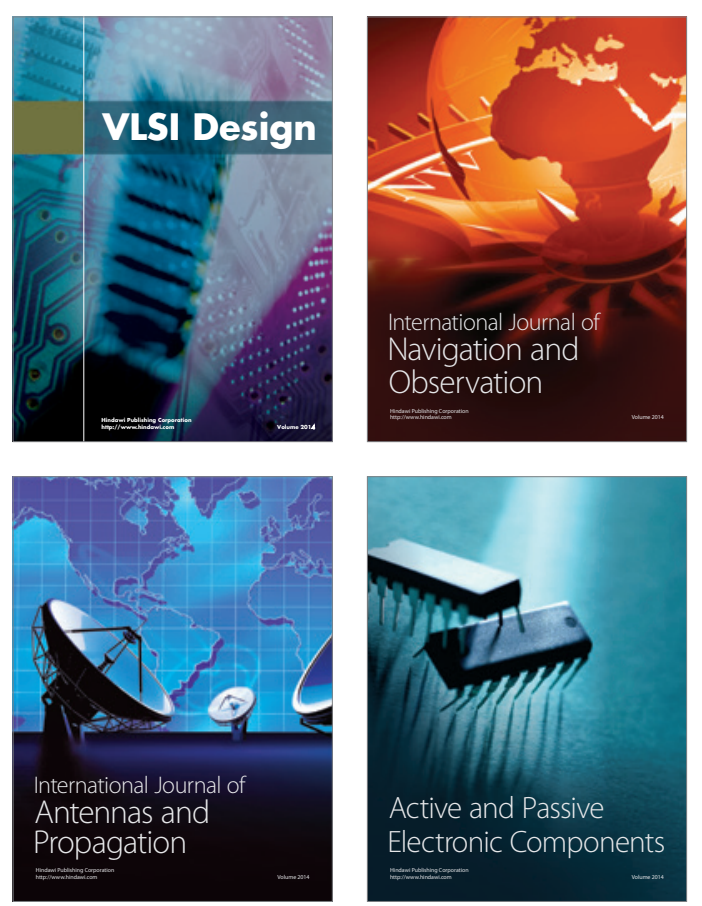
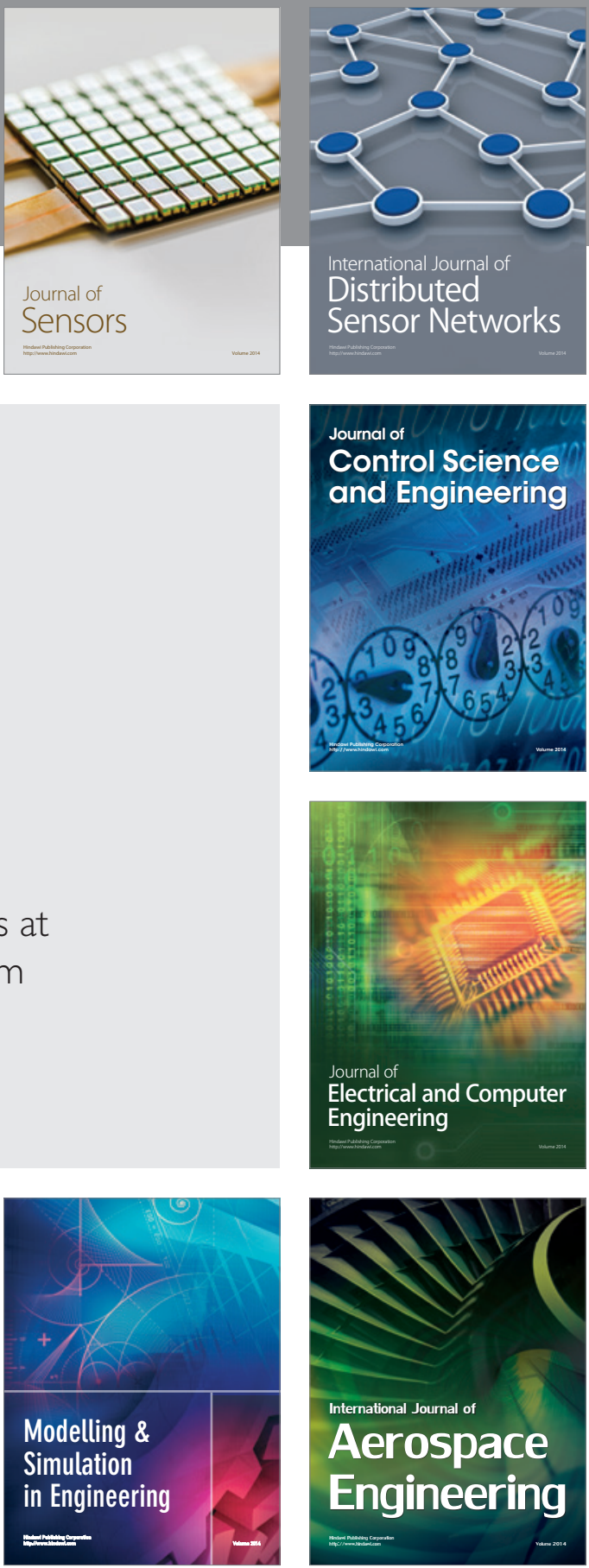

Journal of

Control Science

and Engineering
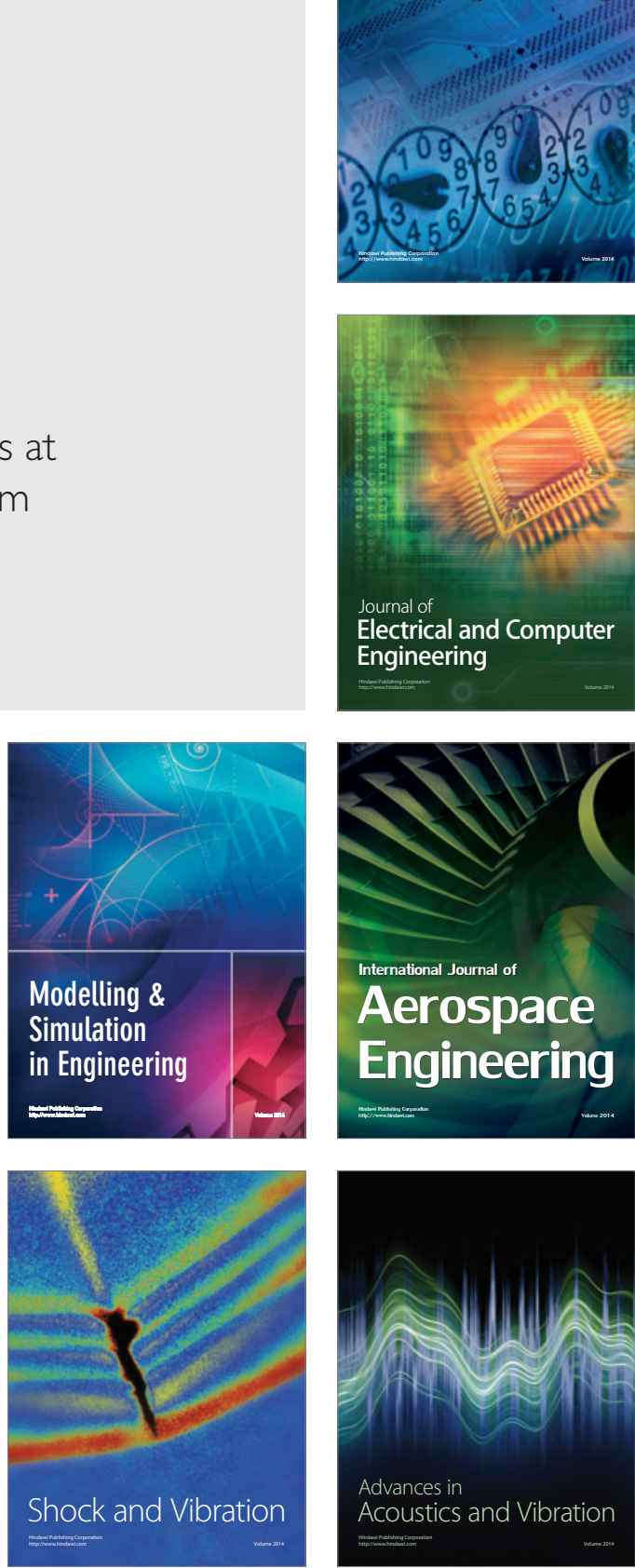